Avogadro's number, leaving nothing behind but their memory. The homoeopathic version of bottled water, which has had negative memories removed and replaced with beneficial energy patterns, is called "Blue Water" and sells for $£ 11$ a litre.

But consumers can only take so much purity. Bottled water has also become an "aquaceutical," the ultimate health food. It is now fortified with additives and produced using special processes claimed to improve health. Nestle, the maker of Contrex bottled water, says its product contains traces of calcium and magnesium that help reduce weight, eliminate toxins, and reduce fatigue. Penta $\mathrm{H} 2 \mathrm{O}$ is claimed to have a unique structure with smaller clusters of $\mathrm{H}_{2} \mathrm{O}$ molecules that ensures more efficient absorption of its health giving properties. Superoxygenated waters claim to increase energy levels and concentration by increasing the concentration of oxygen in the blood. Lakeland Willow Spring water, voted best designer water in 2003, contains traces of salicin, which is claimed by the company to be useful for "eliminating toxins." In California, a company is now selling chemical-free bottled water specifically designed for pets.

Water can also make people feel very vulnerable when they think it has been tampered with. Water contamination incidents are associated with particular disruption and morbidity, which cannot be explained on toxicological grounds. ${ }^{2}$ General Jack Ripper, who believed that fluoridation was a communist plot to poison our "vital body fluids," was a product of Stanley Kubrick's imagination, but his views are only an exaggeration of a widespread concern. The continuing fluoridation controversy confirms that adding anything to public supplies of water causes anxiety.

The public is particularly unforgiving when companies produce water that is less than pure. When high concentrations of benzene were found in Perrier, sales plummeted and the company has struggled to regain its market share. The example of Coca Cola is instructive. Bottled Coca Cola was associated with a health scare in Belgium, which was almost certainly an example of mass hysteria. ${ }^{3}$ The brand was temporarily withdrawn, but sales eventually recovered and the company has not been affected in the long term. On the other hand, when Coca Cola's Dansani water, produced through a process labelled as reverse osmosis developed by NASA, was found to contain concentrations of bromate above the legal limit, the company faced hostility from consumers. Despite the multimillion pound marketing campaign, the company withdrew the product completely from the market.

Bottled water is another of the modern paradoxes of health - a product born out of our success at reducing waterborne disease. In the developing world such diseases cause over two million deaths a year, most of them among children aged under $5 .{ }^{4}$ In these countries, adding chlorine to water is viewed as a health intervention with the potential to save a huge number of lives. In the developed world, bottled water owes part of its popularity to the view that tap water is impure, contaminated, and hence risky. Bottled water is seen as natural, clean, fat-free, and with traces of health giving minerals. In fact tap water is as safe as bottled water and about 1000 times cheaper. The marketing of bottled water exploits people's worries about what affects their health in the modern world. There is a message in that bottle.

Keith J Petrie professor

Health Psychology Department, Faculty of Medicine and Health Sciences, University of Auckland, Private Bag 92019, New Zealand (kj.petrie@auckland.ac.nz)

\section{Simon Wessely professor}

Academic Department of Psychological Medicine, Guy's, King's, and St Thomas' School of Medicine, Institute of Psychiatry, London SE5 8AF (S.Wessely@iop.kcl.ac.uk)

Competing interests: None declared.

Petrie KJ, Wessely S. Modern worries, technological change and medicine: new technologies mean new health complaints. BMJ medicine: new tech

2 David A, Wessely S. The legend of Camelford: medical consequences of a water pollution accident. J Psychosom Res 1995;39:1-10.

3 Nemery B, Fischler B, Boogaerts M, Lison D, Willems J. The Coca-Cola incident in Belgium, June 1999. Food Chem Toxicol 2002;40:1657-67.

4 MacDonald R. Providing the world with clean water. BMJ 2003;327:1416-8.

\title{
In my chosen doctor I trust
}

\author{
And that trust transfers from doctors to organisations
}

$\mathrm{T}$ he season of goodwill provides the occasion to consider the importance of trust in facilitating social intercourse and a well functioning society. ${ }^{1}$ Trust provides the glue that makes cooperation possible without costly and intrusive regulation. Trust has declined in all social institutions in recent decades ${ }^{2}$ and medical leaders in the United States elicit as little public confidence as leaders in government and business. ${ }^{3}$ Trust in doctors has also diminished with the explosion of public information on betrayals of trust, failure to follow evidence based standards, and poor quality care, but patients remarkably retain much trust in their personal doctors. ${ }^{4}$ Such trust encourages sharing of intimate feelings, cooperation in treatment, and adherence to medical advice. ${ }^{5}$ Patients may have assimilated some of the negative media images of doctors and health organisations but they typically believe their doctor is different.
Choosing one's doctor and care settings, continuity of care, and good communication contribute importantly to such trust and to the quality of health care.

When trust erodes, public authorities may appoint expert commissions and introduce new rules and regulations to control substandard and unethical behaviour. They do this to assure the public that health services meet high standards, and that doctors can be trusted. These measures may help, but rarely do they have the high credibility that trusted doctors have in guiding and reassuring patients. ${ }^{6}$

Trust in doctors is built on patients' beliefs that doctors are technically proficient, on interpersonal competence, and on indications that the doctor is their ally. ${ }^{7}$ Typically, patients cannot judge technical competence but assume that educational and certification requirements ensure this. They also use interpersonal 
cues to judge competence, such as how the doctor questions them, communicates about their illness, and answers questions. Some patients judge competencesometimes incorrectly-by the course of their illness and their responses to treatment. Central to patients' trust is how doctors communicate and whether they listen and are caring. Patients do not expect intimacy but they do seek respect and responsiveness. The kinds of communication skills patients value are teachable skills. Finally, patients want to know that their doctors are committed to protecting their interests. Patients in varying contexts may be more or less aware and willing to accept that their doctors are allocators as well as givers of care, but they must feel that their doctors are on their side. The availability of choice reinforces trust in the doctor as agent. ${ }^{8}$

We still know little empirically about the transfer of trust between personal doctors and managers, consultants, hospitals, and the larger health system. Doctors are the gateway to organisational trust. Health plans in the United States elicit trust through the qualifications and reputations of affiliated doctors. Whether the failures of these larger organisations diminish their doctors as well is less clear. In instances where the organisation is held in high public regard, as is the case with the Harvard Medical School, Johns Hopkins Medical School, and the Mayo Clinic, affiliated doctors may also gain in reputation. Doctors and managers stand to benefit by collaborating in building trust in clinicians and in larger systems.

Most patients view medical care in terms of the personal doctor-patient relationship and are not sophisticated about organisational structures and strategies, such as managed care, and how they work. But they want their own doctors, not managers, to control their medical care. This creates a dilemma for managers seeking to reduce variations in care, eliminate inefficiencies, and introduce evidence based standards of care. Managers have to tread carefully, sensitive to the importance of the doctor-patient alliance and the value of trust on which it is often based.

Patients may trust blindly when some scepticism is warranted. Much care that is needed is never provided, and ineffective and inappropriate care is common. ${ }^{9}$ As more information is available for patients in the media and on the internet they often encounter conflicting advice. Patients have many questions about their care and, in the United States, advertising of pharmaceuticals and medical treatments directly to the consumer leads to even more questions. ${ }^{10}$ Few primary care doctors have the time to respond adequately and to make the patient a true partner in care.

Health administrators and managers attempt to deal with such challenges by providing accessible and reliable information to patients, by putting in place disease management programmes that make effective use of nurses and other health professionals, and work with doctors to help them improve their practices. ${ }^{11}$ Electronic information systems offer opportunities to improve communication, avoid errors, and help patients become proactive in their own care. ${ }^{12}$ Managerial interventions carelessly introduced can diminish trust among both health professionals and patients. But if pursued collaboratively they offer potential to promote quality and trust and contribute to satisfaction of both patients and clinicians.

\section{David Mechanic director}

Rutgers, State University of New Jersey Institute for Health, Health Care Policy and Aging Research, 30 College Avenue, New Brunswick, NJ 08901, USA

(mechanic@rci.rutgers.edu)

\section{Competing interests: None declared.}

Misztal BA. Trust in modern societies: the search for the bases of social order Cambridge, MA: Polity Press, 1996.

Nye JS Jr, Zelikow PD, King DC, eds. Why people don't trust government. Cambridge, MA: Harvard University Press, 1997.

3 Focus: News from Harvard Medical, Dental, and Public Health Schools. Initiative looks for ways to build trust. 24 January 2003. http:// focus.hms.harvard.edu/2003/Jan24_2003/research_briefs.html focus.hms.harvard.edu/
(accessed 16 Sep 2004)

4 Jacobs LR, Shapiro RY. Politicians don't pander: political manipulation and the loss of democratic responsiveness. Chicago, London: University of Chicago Press, 2000:237-40.

5 Mechanic D. The functions and limitations of trust in the provision of medical care. J Health Polit Policy Law 1998;23:661-86.

6 The Kaiser Family Foundation, Agency for Healthcare Research and Quality. National survey on Americans as health care consumers: an update on the role of quality information. December 2000. www.kff.org/kaiserpolls loader.cfm? url = $/$ commonspot/security $/$ getfile $c$ fm\&.PageID $=13573$ (accessed 20 Sep 2004).

7 Mechanic D, Meyer S. Concepts of trust among patients with serious illness. Soc Sci Med 2000;51:657-68.

Schmittdiel J, Selby JV, Grumbach K, Quesenberry CP Jr. Choice of a personal physician and patient satisfaction in a health maintenance organization. JAMA 1997;278:1596-9.

9 McGlynn EA, Asch SM, Adams J, Keesey J, Hicks J, DeCristofaro A, et al. The quality of health care delivered to adults in the United States. N Eng J Med 2003;348:2635-45.

10 Mechanic D. Physician discontent: challenges and opportunities. JAMA 2003;290:941-6.

11 Halvorson GC, Isham GJ. Epidemic of care: a call for safer, better, and more accountable health care. San Francisco: Jossey-Bass, 2003.

12 Millenson ML Demanding medical excellence.doctors and accountability in the information age. Chicago: University of Chicago Press, 1997.

\title{
Lifting the fog of uncertainty from the practice of medicine
}

\author{
Strategy revolves around evidence, decision making, and leadership
}

$\mathrm{D}$ espite the exponential growth of medical information, the effects of healthcare interventions are often uncertain or controversial. ${ }^{\mathrm{w} 1}$ This unreliability or uncertainty of all information is what the military philosopher Clausewitz called the fog of war. ${ }^{1}$ Clausewitz maintained that the key to a rational approach to warfare was understanding the impact of chance and the laws of the probability and its interplay with the other factors in war-such as people, governments, and, in particular, the commander in the field. This approach may also benefit health care.

Recently, McNeil argued that the major hidden barriers to better health care result from a lack of discussion of the impact of uncertainty in medicine. ${ }^{2}$ She enumerated several sources of uncertainty that cloud

Additional references w1-w8 are on bmj.com 